\title{
INTERNODAL CAVITY DEFORMATION IMPROVED BENDING STRENGTH OF BAMBOO
}

\author{
Meng J* \& Sun DG \\ Taiyuan University of Science and Technology, Taiyuan, 030024, China \\ *mengturbo@163.com
}

Submitted July 2020; accepted October 2020

\begin{abstract}
Due to various applications of bamboo as a loading structure, it is necessary to have a deep understanding of the relationship between its morphology and mechanics, including how its structure adapts to taking the applied load. In this paper, diaphragms are considered concave or convex rather than flat plates. Two kinds of cavities (concave and convex) comprising internodal tubes and diaphragms were studied. One loaded bamboo model was established to deduce the formulas for the deformation amount of cavity volume (concave and convex cavities). Variations of their volume and inner radius, internode length, the curve surface depth, and the shortening rate were analysed. The deformation of one loaded bamboo with actual shortening rate $(0-0.3)$ was simulated by software. The result revealed that bamboo culms showed wavy deformation as the two cavities alternately appeared. The concave cavity shrinkage restrained further deformation, while the convex cavity expansion gave rise to further deformation. Both cavities interacted to improve the bending strength of bamboo culms and prevented large deformation or fractures. This study could provide new ideas and methods for the design of structures with desired bending performance.
\end{abstract}

Keywords: Node diaphragm, internodal tube, concave cavity, convex cavity, volume variation

\section{INTRODUCTION}

Bamboo has considerable potential to be widely used in construction, machinery, vehicles, aerospace, and other engineering fields due its significantly higher flexural ductility and better strength properties (Chen et al. 2020). The bamboo plant grows as a series of hollow tubes with periodic nodes characterised by an internal diaphragm and an external ridge (Kappel et al. 2004). Mechanically, its evolved structure plays an important role in allowing the plant to achieve excellent properties to keep the bamboo culms upright and prevent failure. Many scholars have analysed the mechanical behaviour of bamboo in terms of internodal tubes and nodes. The shear, compression, and tension of bamboo at nodes and internodes increase from bottom to top (Gusti et al. 2014). Herarchical structural features of bamboo contribute to its compression capacity and the longer internode length yields higher buckling resistance (Cui et al. 2020). Bamboo culm stiffness, strength, and toughness are weak at the nodes (David et al. 2015). Bamboo node improves the stiffness and stability of the bamboo culms during growth (Shao et al. 2010) and prevents local buckling (Kappel et al. 2004).
Bamboo joint exerts a significant influence on the mechanical performance of bamboo culms as a whole (Taylor et al. 2015). Bamboo nodes play a critical role in avoiding strong deformation under the wind load. The more nodes there are, the less the stress along the bamboo culm, and the smaller the outer diameter compression (Meng et al. 2018). Bamboo node is a point of weakness when loaded in tension. Meanwhile, structural features, such as external ridge and internal diaphragm, strengthen the node (Wang et al. 2011).

Our understanding of structural features and the mechanical performance of bamboo under different loading conditions is limited. Extensive research has been done on the mechanical properties of bamboo by treating internal diaphragms as flat plates. It is not known how these diaphragms bear the load capacity. Internal diaphragms are not flat, instead they are concave or convex. These two types of diaphragms are distributed at intervals, which make up the closed concave or convex cavity with an internodal tube (Figure 1). In this study, each closed cavity (concave or convex) was treated as a unit and 




Figure 1 Structural features of bamboo

we investigated how the cavities adjusted their volumes to a loaded bamboo culm to achieve excellent bending strength. A bending bamboo model was set up and the formulas for volume deformation of cavities were deduced to discuss how volume variation changed along with related parameters. Findings would illustrate the influence of bamboo nodes on bending behaviour of bamboo culm with respect to the cavity deformation and inspire the structural engineers to take into account this characteristic to create a bio-mimicking strong structure.

\section{MATERIALS AND METHODS}

\section{Loaded bamboo model}

As bamboo culm bent under loading F (Figure 2 ), so did the concave and convex cavities. Mature bamboo had more than 40 nodes, thus the bending deflection of a single bamboo tube was insignificant, and was ignored in this study. Consequently, the radial dimension decreased along the $\mathrm{y}$-axis but increased along the $\mathrm{x}$ - and the z-axes (Figures 3 and 4). Before loading, the radial section of the bamboo tube was a circle with radius $r$. The space enclosed by a curved diaphragm was part of a sphere with radius R. The cavity was a closed space with evenly distributed internal pressure, and its volume $V_{1}$ was given as:

$$
\mathrm{V}_{1}=\frac{\pi}{\mathrm{h}}\left[\frac{\left(\mathrm{r}^{2}+\mathrm{h}^{2}\right)^{2}}{\mathrm{~h}} \arcsin \frac{\mathrm{h}}{\sqrt{\mathrm{r}^{2}+\mathrm{h}^{2}}}-\frac{\mathrm{r}}{2}\left(\mathrm{r}^{2}-\mathrm{h}^{2}\right)\right]
$$

where $\mathrm{h}$ is the depth of space enclosed by a curved diaphragm. Accordingly, the volume and

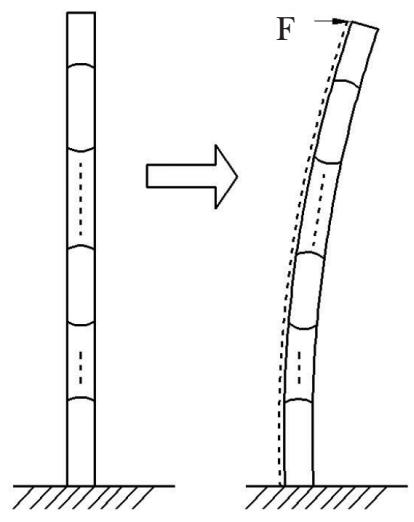

Figure 2 Bending bamboo culm

the internal pressure of the concave cavity were written as $\mathrm{V}_{2}=\pi \mathrm{r}^{2} 1-2 \mathrm{~V}_{1}$ and $\mathrm{P}_{2}$ respectively, while the volume and internal pressure of the convex cavity were expressed as $\mathrm{V}_{3}=\pi \mathrm{r}^{2} 1+2 \mathrm{~V}_{1}$ and $\mathrm{P}_{3}$ respectively.

The radial section turned into an ellipse when the bamboo culm was loaded (Figures 3 and 4) and the radial dimension changed into $\mathrm{r}(1-\xi)$ along the y-axis. where $\xi$ is the shortening rate. The enclosed space became part of an ellipsoid with $b_{1}, b_{2}$, and $b_{3}$ as the semi-axis lengths in $x, y$, and $\mathrm{x}$ directions respectively. The volume of the ellipsoid, $\mathrm{V}_{1}^{\prime}$, was expressed as follows:

$$
\begin{aligned}
\mathrm{V}_{1}^{\prime}= & \frac{1}{24 \mathrm{~h}^{3}}\left[\pi-\arcsin \left(\frac{\mathrm{r}^{2}-\mathrm{h}^{2}}{\mathrm{r}^{2}+\mathrm{h}^{2}}\right)\right] \\
& \left(\mathrm{r}^{2}-\mathrm{h}^{2}\right)(1-\xi)\left(\frac{\pi}{2} \xi-\xi+1\right) \\
& \cos \frac{2 \sqrt{2 \mathrm{r}}(1-\xi)}{\sqrt{\left(\mathrm{r}^{2}+\mathrm{h}^{2}\right)^{2}(\pi \xi-2 \xi+2)^{2}-2 \pi \mathrm{r}^{2} \xi \mathrm{h}(\pi \xi-4 \xi+4)}}
\end{aligned}
$$

Accordingly, the loaded volume $\mathrm{V}_{2}^{\prime}$ of the concave cavity was calculated using equation 3 :

$$
\mathrm{V}_{2}^{\prime}=\pi \mathrm{r}^{2}\left(\frac{\pi}{2} \xi-\xi+1\right)^{2}-2 \mathrm{~V}_{1}^{\prime}
$$

and $\mathrm{V}_{3}$ of the convex cavity was written as:

$$
\mathrm{V}_{3}^{\prime}=\pi \mathrm{r}^{2}\left(\frac{\pi}{2} \xi-\xi+1\right)^{2}+2 \mathrm{~V}_{1}^{\prime}
$$

The cavity volume was inversely proportional to its internal pressure on account of $\mathrm{VP}=\mathrm{C}(\mathrm{C}$ is a constant) and evenly distributed internal 

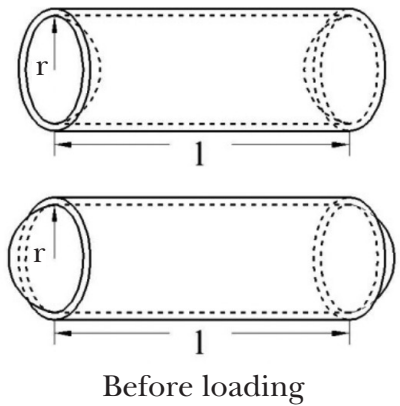

Before loading

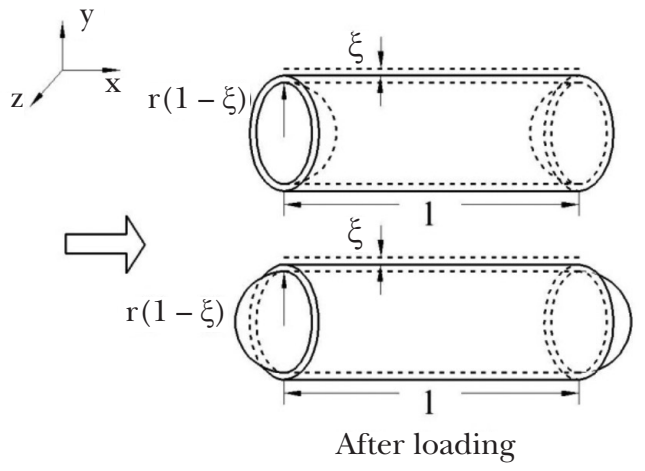

Figure 3 Cavity deformation; $r$ = radius of radial section before loading, $1=$ internodal length, $\xi=$ shorting rate
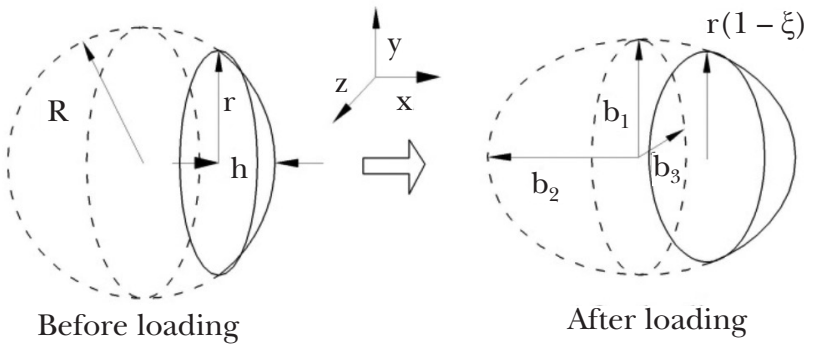

Figure 4 Diaphragm deformation; $\mathrm{R}$ = radius of sphere before loading, $\mathrm{h}$ = depth of space enclosed by a curved diaphragm before loading, $b_{1}, b_{2}$ and $b_{3}=$ semi-axis lengths in three directions after loading

pressure. Under loading $\mathrm{F}$, volume variations of the two types of cavities were $\Delta \mathrm{V}_{2}=\mathrm{V}_{2}-\mathrm{V}_{2}^{\prime}$ and $\Delta \mathrm{V}_{3}=\mathrm{V}_{3}-\mathrm{V}_{3}^{\prime}$. If the volume increases, the internal pressure decreases and the cavity continues to deform. Conversely, if the internal pressure increases with decreasing volume, the cavity deformation is suppressed.

\section{Measurement of parameters}

Growth site can influence the physical properties of bamboo (Aguinsatan et al. 2019). Age not only influences the mechanical properties of bamboo but also its suitability and durability (Abd Latif et al. 1990). Therefore, 50 mature bamboos (Phyllostachys pubescens, 5 years old) were randomly collected from Hunan province in China and measured in air-dry condition. A length of $10 \mathrm{~m}$ was cut from bottom to top. The inner diameter (2r) was measured using vernier callipers with a measuring range of $0-1000 \mathrm{~mm}$ and an accuracy of up to $\pm 0.02 \mathrm{~mm}$. Curve surface depth (i.e. the depth of space enclosed by a curved diaphragm, h) was measured using callipers with a measuring range of $0-150 \mathrm{~mm}$ with $\mathrm{a} \pm 0.05 \mathrm{~mm}$ accuracy. Internodal length
1 was measured using a tape with a measuring range of $0-5000 \pm 1 \mathrm{~mm}$. Statistically, the inner radius $\mathrm{r}$ ranged from 20 to $70 \mathrm{~mm}$, the curve surface depth $\mathrm{h}$ from 0.3 to $30 \mathrm{~mm}$, and the internodal length 1 from 100 to $290 \mathrm{~mm}$.

\section{RESULTS AND DISCUSSION}

Volume variations of the two types of cavities were obtained by plugging measured parameters $(\mathrm{r}, \mathrm{l}$, and $\mathrm{h}$ ) and the shortening rate $\xi(0-0.9)$ into the above formulas.

\section{Volume variation of the concave cavity}

Figure 5 shows how the volume variation $\Delta \mathrm{V}_{2}$ changed with $\mathrm{r}$ when $\xi=0.1,0.3,0.5,0.9$ and $1=100-290 \mathrm{~mm} \cdot \Delta \mathrm{V}_{2}$ increased with $\mathrm{r}$, and the larger the value of 1 , the more rapidly $\Delta \mathrm{V}_{2}$ increased. When $\mathrm{l}=290 \mathrm{~mm}$ and $\mathrm{r}=70 \mathrm{~mm}, \Delta \mathrm{V}_{2}$ with $\xi=0.9$ was twice the value compared with when $\xi=0.1$. Thus, the greater the value of $\xi$, the larger was the value of $\Delta \mathrm{V}_{2}$.

Figure 6 shows the change rule of $\Delta \mathrm{V}_{2}$ along with $\mathrm{h}$ under the similar $\xi$ values. $\Delta \mathrm{V}_{2}$ decreased with $\mathrm{h}$, and the larger the value of $\mathrm{l}$, the faster $\Delta \mathrm{V}_{2}$ 


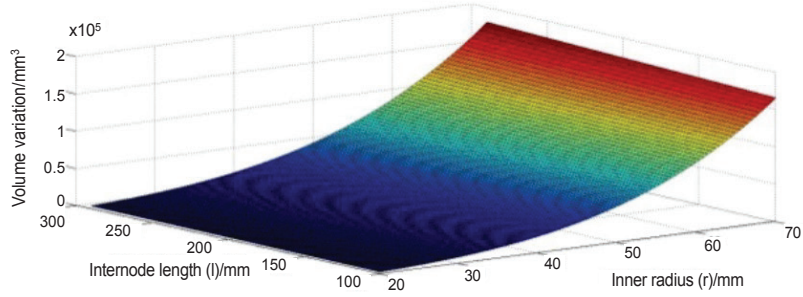

(a) $\xi=0.1$

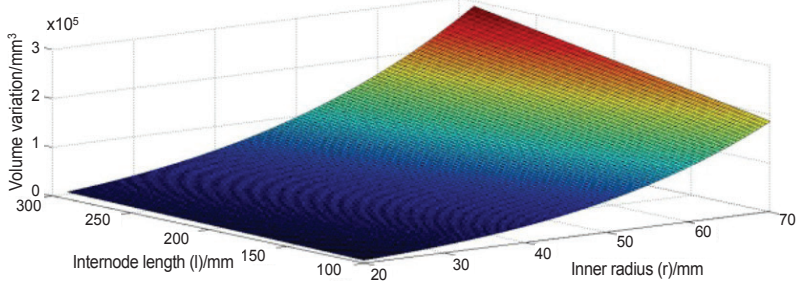

(c) $\xi=0.5$

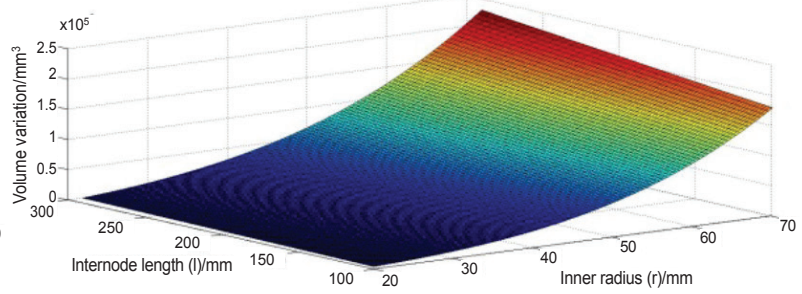

(b) $\xi=0.3$

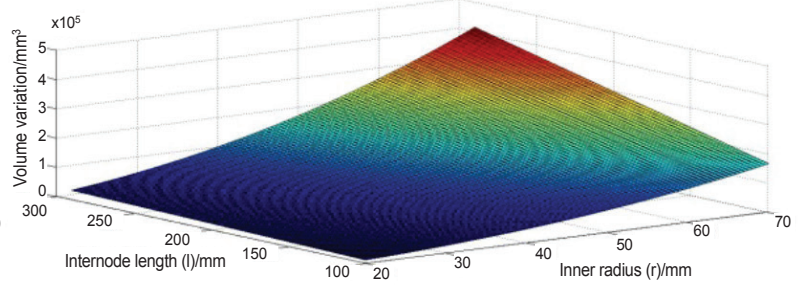

(d) $\xi=0.9$

Figure 5 Volume variation $\mathrm{V}_{2}$ along with the inner radius $\mathrm{r}$

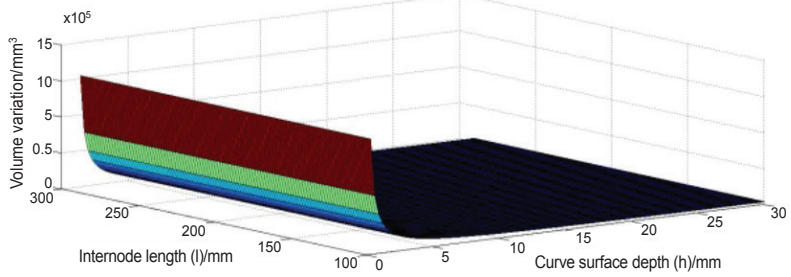

(a) $\xi=0.1$

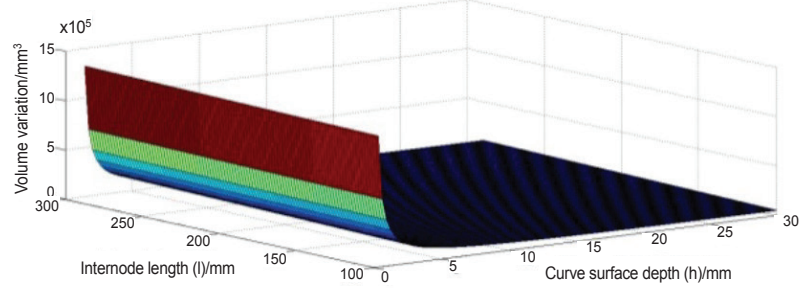

(c) $\xi=0.5$

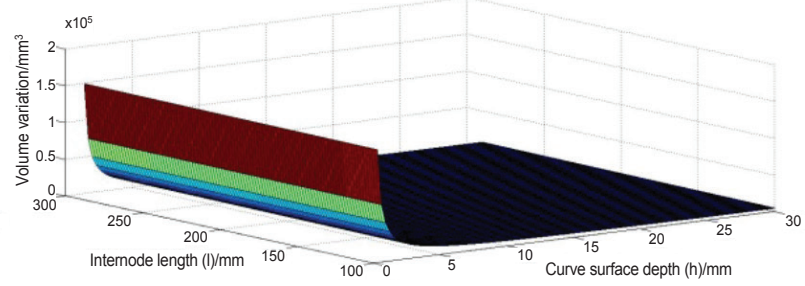

(b) $\xi=0.3$

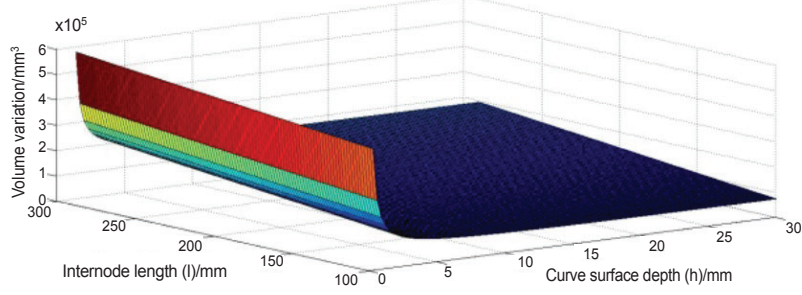

(d) $\xi=0.9$

Figure 6 Volume variation $\mathrm{V}_{2}$ along with the curve surface depth $\mathrm{h}$

decreased. When $\mathrm{l}=290 \mathrm{~mm}$ and $\mathrm{h}=0.3 \mathrm{~mm}, \Delta \mathrm{V}_{2}$ with $\xi=0.9$ was $60 \%$ less than that when $\xi=0.1$, meaning, the greater the value of $\xi$, the smaller was the value of $\Delta V_{2}$.

\section{Volume variation of the convex cavity}

Figure 7 shows the change rule of $\Delta \mathrm{V}_{3}$ along with $\mathrm{r}$ under the same condition. $\Delta \mathrm{V}_{3}$ decreased with $\mathrm{r}$ when $\xi=0.1$ and the smaller the value of 1 , the more rapidly $\Delta \mathrm{V}_{3}$ decreased. When $\xi=0.3$ and $\mathrm{r}$ $<30 \mathrm{~mm}, \Delta \mathrm{V}_{3}$ increased with $\mathrm{r}$ but when $\mathrm{r}>30$ $\mathrm{mm}, \Delta \mathrm{V}_{3}$ decreased with $\mathrm{r}$, and the smaller the value of 1 , the more quickly $\Delta \mathrm{V}_{3}$ decreased when $\xi=0.5$, and if $\mathrm{r}<30 \mathrm{~mm}, \Delta \mathrm{V}_{3}$ increased with $\mathrm{r}$ but if $\mathrm{r}>30 \mathrm{~mm}$ and $1<150 \mathrm{~mm}, \Delta \mathrm{V}_{3}$ decreased with $\mathrm{r}$. The smaller the value of 1 , the faster $\Delta \mathrm{V}_{3}$ decreased. When $r>30 \mathrm{~mm}$ and $1>150 \mathrm{~mm}$, initially $\Delta \mathrm{V}_{3}$ increased but later decreased, and the greater the value of 1 , the larger was the range of $\Delta V_{3}$ increasing with $r$. In addition, the larger the peak value was, the smaller was the range of $\Delta \mathrm{V}_{3}$ decreasing with $\mathrm{r}$. When $\xi=0.9$, $\Delta V_{3}$ increased with $r$, and the greater the value 


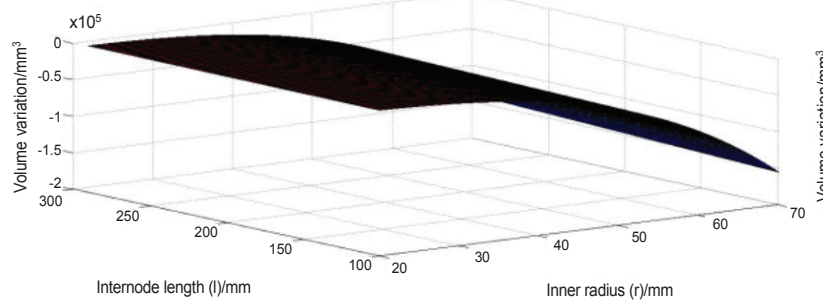

(a) $\xi=0.1$



(c) $\xi=0.5$

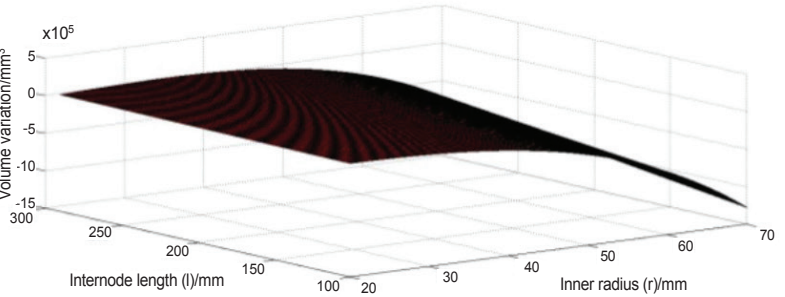

(b) $\xi=0.3$

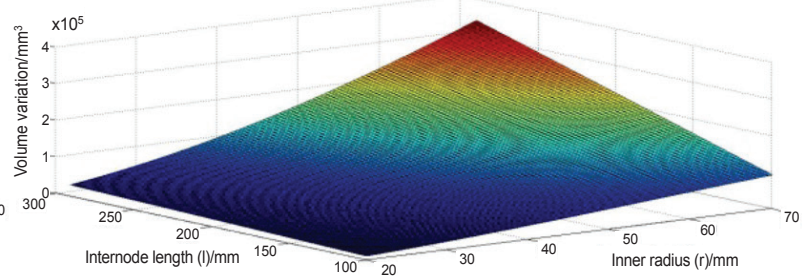

(d) $\xi=0.9$

Figure 7 Volume variation $\mathrm{V}_{3}$ along with the inner radius $\mathrm{r}$

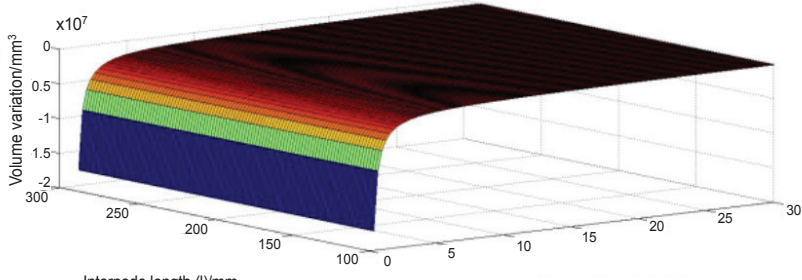

Internode length (1)/mm

(a) $\xi=0.1$

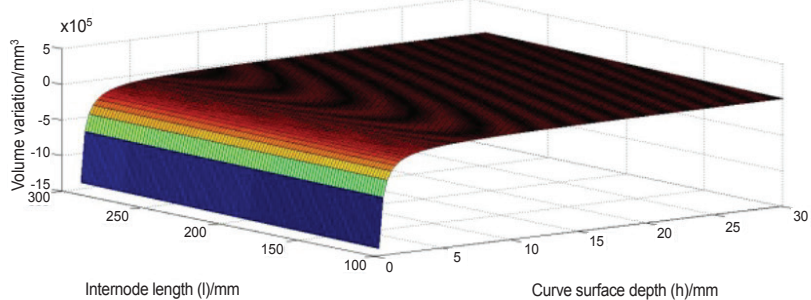

(c) $\xi=0.5$



(b) $\xi=0.3$

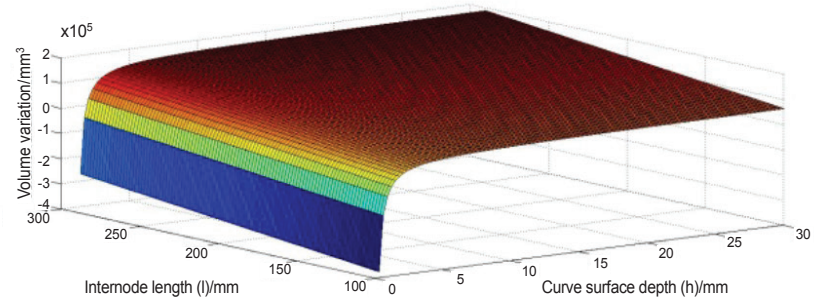

(d) $\xi=0.9$

Figure 8 Volume variation $V_{3}$ along with the curve surface depth $h$

of 1 , the faster $\Delta \mathrm{V}_{3}$ increased. Figure 8 shows the change rule of $\Delta \mathrm{V}_{3}$ along with $\mathrm{h}$ under the same condition. $\Delta \mathrm{V}_{3}$ increased with $\mathrm{h}$, and the larger the value of 1 , the faster $\Delta \mathrm{V}_{3}$ increased, and the greater the value of $\xi$, the larger the value of $\Delta \mathrm{V}_{3}$.

With the above results, bamboo size and the actual shortening rate (0-0.3) (Shao et al. 2003), bamboo deformation under loading was simulated by software. The initial deformation occurred in cavities under the loading. For concave cavity, its volume shrank and the internal pressure increased, which restrained further deformation. Accordingly, it restrained bending of the bamboo culm, improved its structural strength and reserved energy for the bamboo to go back to its original position. For convex cavity, its volume expanded and the 


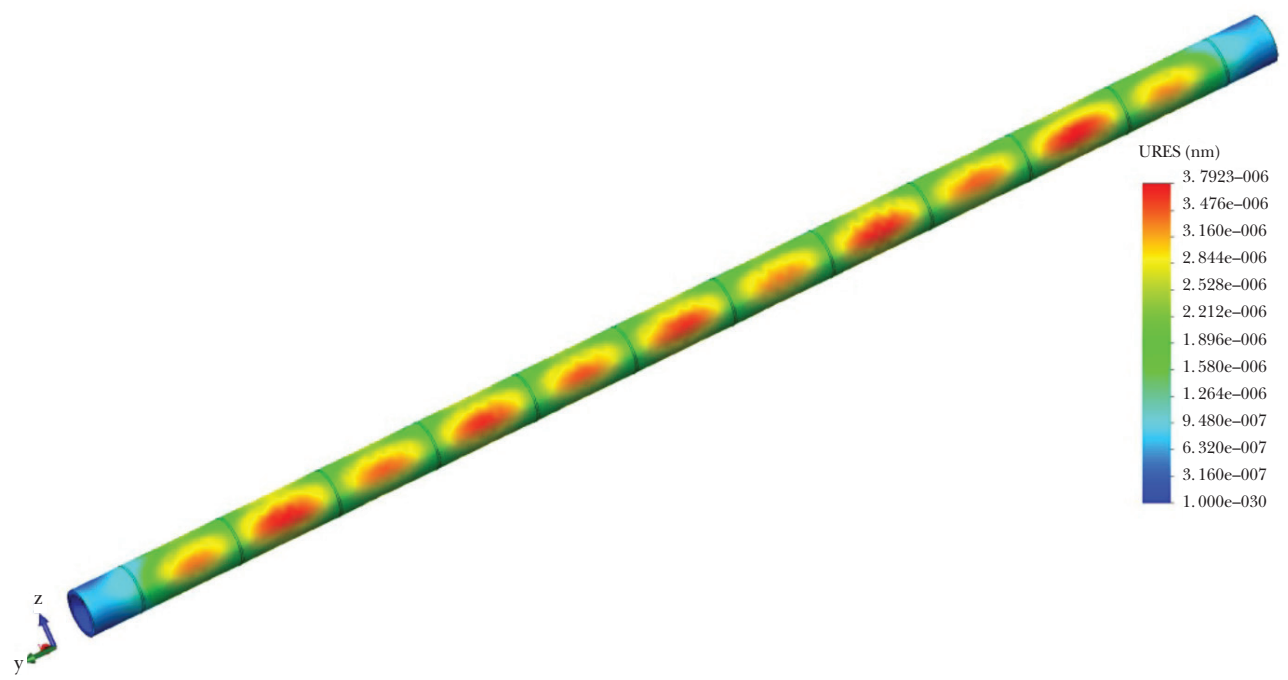

Figure 9 Bamboo culm deformation

internal pressure decreased, causing further deformation. Thus, it buffered the shock from the instantaneous loading and avoided large deformation or fractures. This indicated that bamboo culms alternated between the contractive concave cavity and the expansive convex cavity (Figure 9). Deformation along the bamboo culm was not uniform, but had a wavy pattern with increasing bamboo height. The alternate arrangement of the two cavities can effectively alleviate the impact and damage from external loads. It can also adjust the structural strength of the bamboo under different loading conditions to ensure that the bamboo is not destroyed and can recover to its natural state.

\section{CONCLUSIONS}

A loaded bamboo culm presented wavy deformation because concave and convex cavities were arranged alternately along its length. Volume shrinkage of the concave cavity restrained further deformation, while volume expansion of the convex cavity led to further deformation. The interaction of these cavities contributed to the excellent bending performance of the bamboo. Findings and data of this study could be helpful for the bio-inspired design of advanced structures with excellent bending strength. For future work, an intensive study is needed on how the shape characteristics and the deformation behaviour of concave and convex cavities at different heights above the ground influence the bending performance of the whole bamboo culm.

\section{ACKNOWLEDGMENTS}

The authors wish to express their sincere thanks to Liu SZ, Yan BJ and Song Y of Damping Vibration Attenuation Laboratory of Taiyuan University of Science and Technology for their general guidance and technical advice. This study was supported by Shanxi Basic Research for Application Project (No:201901D211293) and Shanxi Scientific Innovation Project (No:2020L0339).

\section{REFERENCE}

Abd Latif M, Wan TWA \& Fauzidah A. 1990. Anatomical features and mechanical properties of three Malaysian bamboos. Journal of Tropical Forest Science 2: 227-234.

Aguinsatan RG, Razal RA, Carandang MG \& Peralta EK. 2019. Site influence on the morphological, physical and mechanical properties of giant bamboo (Dendrocalamus asper) in Bukidnon province, Mindanao Philippines. Journal of Tropical Forest Science 31: 99-107. doi: 10.26525/jtfs2019.31.1.099107

Chen ML, Ye L, Li H, Wang G, Chen Q, Fang CH, Dai CP \& FEI BH. 2020. Flexural strength and ductility of moso bamboo. Construction and Building Material 246: 118418. doi: 10.1016/j.conbuildmat.2020.118418

Cui JH, Qin Z, Admir M \& Markus JB. 2020. Multiscale structural insights of load bearing bamboo: a computational modeling approach. Journal of the Mechanical Behavior of Biomedical Materials 107: 103743. doi: 10.1016/j.jmbbm.2020.103743

David T, Billy K, Ciara S, Darragh S, Peter O'R \& Kai D. 2015. The biomechanics of bamboo: investigating the role of the nodes. Wood Science Technology 49: 345-357. doi: 10.1007/s00226-014-0694-4 
Gusti MO, Andreas T, Ali A \& Suprapto S. 2014. Effects of node, internode and height position on the mechanical properties of Gigantochloa atroviolacea bamboo. Procedia Engineering 95: 31-37. doi: 10.1016/j.proeng.2014.12.162

Kappel R, Matteck C, Bethge K \& Tesari I. 2004. Bamboo as a composite structure and its mechanical failure behavior. Pp 285-293 in Collins M \& Brebbia CA (eds) Design and Nature II: Comparing Design in Nature With Science and Engineering. WIT Press, Southampton.

MENG J \& Sun DG. 2018. The effects of the node distribution on the bending strength of bamboo. Journal of Tropical Forest Science 30: 554-559. doi: 10.26525/ jtfs2018.30.4.554559

SHAO ZP. 2003. Mechanical behavior of bamboo with large deformation: I. The relationship between stress and strain. China Wood Industry 17: 12-15. doi: 10.19455/j. mcgy.2003.02.004
Shao ZP, Zhou L, Liu YM, Wu ZM \& Arnaud C. 2010. Differences in structure and strength between internode and node sections of moso bamboo. Journal of Tropical Forest Science 22: 133-138. doi: 10.1007/s10310-009-0161-5

Taylor D, Kinane B, Sweeney C, Sweetnam D, O'reilly P \& Duan K. 2015. The biomechanics of bamboo: investigating the role of the nodes. Wood Science Technology 49: 345-357. doi:10.1007/s00226-0140694-4

Wang X, Ren H, Zhang B, Fei B \& Burgert I. 2011. Cell wall structure and formation of maturing fibres of moso bamboo (Phyllostachys pubescens) increase buckling resistance. Journal of the Royal Society Interface 9: 988-996. doi:10.1098/rsif.2011.0462 